\title{
Catalytic Asymmetric Allylation of Aldehydes with Alkenes Mediated by Organophotoredox and Chiral Chromium Hybrid Catalysis
}

\author{
Harunobu Mitsunuma, ${ }^{*},{ }^{\dagger}$ Shun Tanabe,${ }^{\dagger}$ Hiromu Fuse, ${ }^{\dagger}$ Kei Ohkubo,,${ }^{\dagger}$ and Motomu Kanai ${ }^{*}, \dagger$ \\ ${ }^{\dagger}$ Graduate School of Pharmaceutical Sciences, The University of Tokyo, Tokyo 113-0033, Japan \\ ¥Institute for Advanced Co-Creation Studies and Institute for Academic Initiatives, Osaka University, Osaka 565-0871, Japan
}

Supporting Information Placeholder

\begin{abstract}
A hybrid system accomplishing cooperativity between an organophotoredox acridinium catalyst and a chiral chromium complex catalyst was developed, enabling the unprecedented exploitation of unactivated hydrocarbon alkenes as precursors to chiral allylchromium nucleophiles for the asymmetric allylation of aldehydes. The reaction proceeded under visible light irradiation at room temperature and with high functional group tolerance, affording the corresponding homoallylic alcohols with up to $>20 / 1$ diastereomeric ratio and $99 \%$ ee. The addition of $\mathrm{Mg}\left(\mathrm{ClO}_{4}\right)_{2}$ elicited profound enhancement of both reactivity and enantioselectivity.
\end{abstract}

The catalytic asymmetric allylation of aldehydes to produce enantiomerically enriched secondary homoallylic alcohols represents a fundamental process in synthetic organic chemistry. ${ }^{1}$ The methodology developed to this end thus far can be classified into three main categories. Firstly, chiral Lewis acids, Lewis bases, and Brønsted acids have been used to promote the reaction of preactivated allylmetal species, such as allyltin, -silicon, and -boron reagents (Figure 1(a)). ${ }^{1}$ Alternatively, the Nozaki-Hiyama-Kishi (NHK) allylation is a chromium-mediated reductive $\mathrm{C}-\mathrm{C}$ bondforming reaction using allylic halides as precursors to nucleophilic allylchromium intermediates. ${ }^{2}$ Despite their high reactivity towards carbonyl groups, these allylchromium species exhibit broad functional group tolerance, enabling the NHK reaction to be extensively applied to multifunctional substrates in complex molecule synthesis. ${ }^{3}$ Based on the pioneering work by Fürstner, ${ }^{4}$ who developed the first catalytic NHK reaction (using manganese(0) as a stoichiometric reductant and $\mathrm{TMSCl}$ as a catalyst turnover facilitator), many catalytic asymmetric variants of the NHK allylation have been reported (Figure 1(b)). ${ }^{3 b, 3 c, 5}$ However, there still remains room for improvement in the two traditional methods represented by Figure 1(a) and 1(b), particularly in their overall efficiency and redox/atom/step economy. To address these issues, Krische reported the versatile catalytic asymmetric coupling of primary alcohols with dienes/allenes under transfer hydrogenative conditions (Figure 1 (c)), but this powerful method has not yet utilized cyclic dienes as pronucleophiles. ${ }^{6}$ During our study, Glorius' group reported an elegant diastereoselective allylation of aldehydes mediated by an iridium photoredox/chromium hybrid catalysis. Their racemic reaction utilized electron-rich aromatic- or amine-substituted alkenes as precursors for allylchromium nucleophiles to facilitate photocatalyzed single-electron oxidation. A preliminary application to an asymmetric variant was reported for one substrate combination, but the enantioselectivity was only $20 \%$ ee. $^{7}$ Herein we report an asymmetric hybrid catalyst system comprising an organophotoredox catalyst and a chiral chromium complex catalyst, which enables the asymmetric allylation of aldehydes by nucleophilic chiral allylchromium species generated in situ from unactivated hydrocarbon alkenes by $\mathrm{C}\left(s p^{3}\right)-\mathrm{H}$ bond activation (Figure 1(d)). 8,9 (a) Using preactivated allylmetals

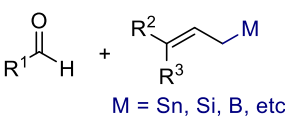

chiral acid or base Brønsted acid catalyst

chiral Ru or Ir catalyst<smiles>[R]C([R])=C=C</smiles>

(c) Krische reaction (b) Nozaki-Hiyama-Kishi reaction

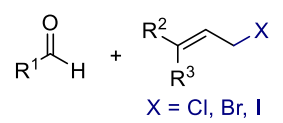

chiral $\mathrm{Cr}$ catalyst TMSCI, Mn photoredox catalyst

chiral $\stackrel{+}{\mathrm{C}}$ catalyst<smiles>[R]C([CH2+])=O</smiles>

(d) This work

Figure 1. Four strategies for catalytic asymmetric allylation of aldehydes. (a) Chiral Lewis acid/base or Brøsted acid-catalyzed reactions using preactivated allylmetals as nucleophiles. Metal-derived waste is generated, and synthesis of allylmetal reagents requires additional steps. (b) Chiral chromium complex-catalyzed NHK reaction. Halide-, silicon-, and manganese-derived waste is generated. (c) Krische reaction. The reaction proceeds with high atom economy, but the scope does not extend to cyclic dienes. (d) This work. The reaction proceeds through photoredox catalyst-mediated allylic $\mathrm{C}\left(s p^{3}\right)-\mathrm{H}$ metalation of unactivated alkenes, generating chiral allylchromium nucleophiles. 


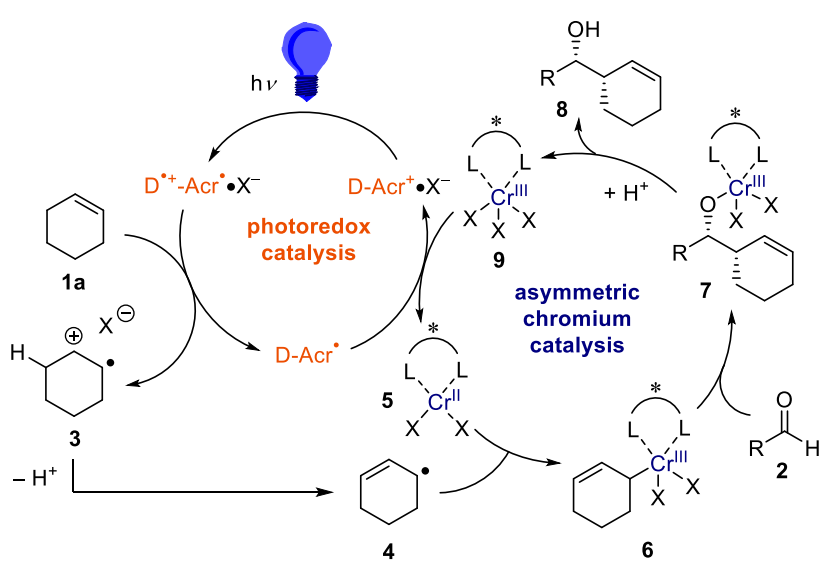

Figure 2. Proposed catalytic cycle.

Our mechanistic rationale for this transformation is illustrated in Figure 2. Based on precedent from the Wu laboratory, ${ }^{10}$ allyl radical 4 should be accessible from alkene 1a via single-electron oxidation of the $\pi$-bond by a photoexcited electron-donor substituted acridinium catalyst $\left(\mathrm{D}^{\circ+}-\mathrm{Acr} ; \mathrm{D}=2,6\right.$-xylyl and 2,4,6-mesityl) to generate radical cation 3 , followed by deprotonation. A reduced form of the chiral chromium(II) catalyst 5 would then intercept the thus-formed allyl radical 4 to give chiral allyl chromium(III) complex 6. It was anticipated that this species would react with aldehydes 2 via a six-membered chair transition state to produce enantiomerically-enriched chromium alkoxide 7 in a syn-selective fashion. Protonolysis of $\mathbf{7}$ should then afford the target homoallylic alcohol 8 and an oxidized chromium(III) complex 9. Finally, singleelectron reduction of $\mathbf{9}$ by the reduced form of the photocatalyst (D-Acr ) would regenerate $\mathbf{5}$ and the oxidized form of the photocatalyst $\left(\mathrm{D}-\mathrm{Acr}^{+}\right)$, thus closing the catalytic cycle. ${ }^{11}$ Photocatalyzed $\mathrm{C}\left(s p^{3}\right)-\mathrm{H}$ bond activation followed by oxidative interception of the resulting carbon-centered radical by a metal complex (i.e., corresponding to the process from 1a to 6 in Figure 2) is an emerging method for the catalytic generation of organometallic species from substrates traditionally considered inert. ${ }^{12-14}$ However, employment of the organometallic intermediates generated by this method has mainly been limited to cross-coupling reactions. Extension of the chemistry to facilitate addition of these nucleophiles to polar moieties, such as carbonyl groups, has been hitherto unexplored with the exception of one recent report by the Glorius group. ${ }^{7,15}$

\section{Table 1. Optimization of Reaction Conditions ${ }^{a}$}

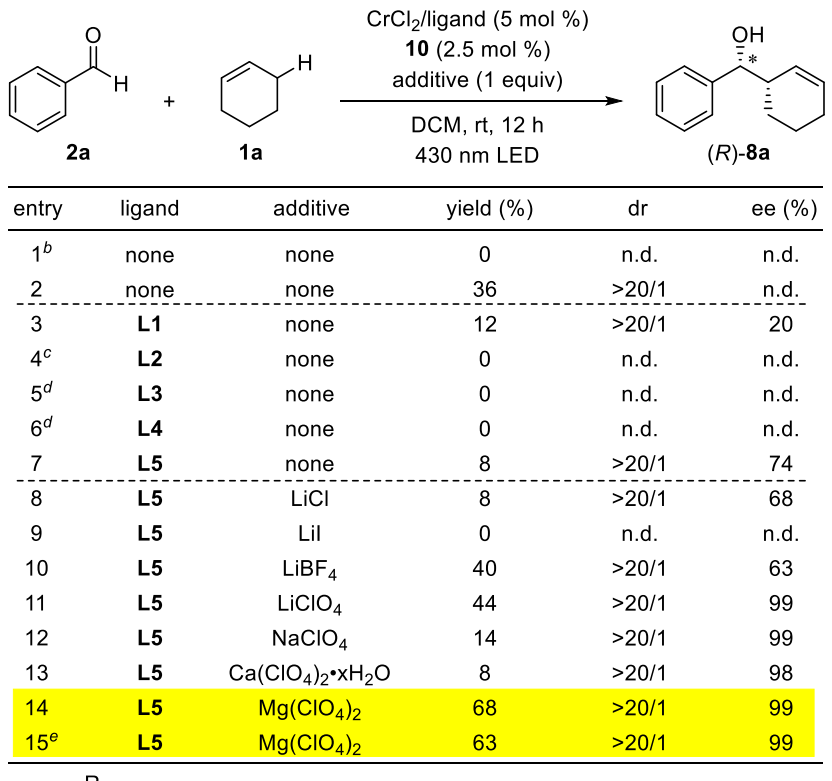

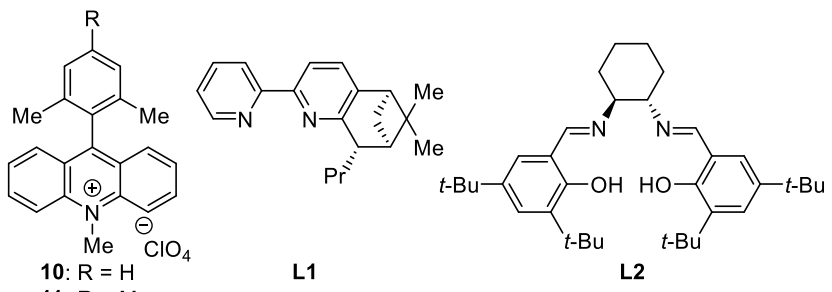

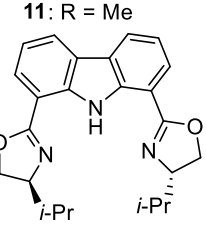

L3

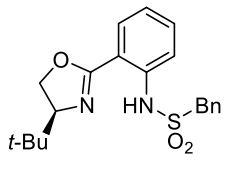

L4

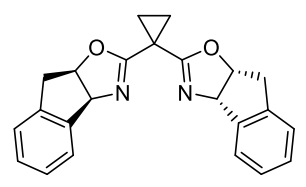

L5
${ }^{a}$ General reaction conditions: $\mathbf{2 a}(0.25 \mathrm{mmol}), \mathbf{1 a}(5.0 \mathrm{mmol}), \mathrm{CrCl}_{2}$ $(0.0125 \mathrm{mmol})$, ligand $(0.0125 \mathrm{mmol}), \mathbf{1 0}(0.00625 \mathrm{mmol})$, and additive $(0.25 \mathrm{mmol})$ were reacted in dichloromethane (DCM; 2.5 $\mathrm{mL}$ ) at room temperature under $430 \mathrm{~nm}$ LED irradiation for $12 \mathrm{~h}$. Yield and dr were determined by ${ }^{1} \mathrm{H}$ NMR analysis of the crude mixture using 1,1,2,2-tetrachloroethane as an internal standard. The ee of 8a was determined by chiral stationary HPLC analysis after isolation. n.d. $=$ Not determined. ${ }^{b}$ Without $\mathrm{CrCl}_{2} .{ }^{c} 10 \mathrm{~mol} \% \mathrm{Et}_{3} \mathrm{~N}$ was added. ${ }^{d} 5 \mathrm{~mol} \% \mathrm{Et}_{3} \mathrm{~N}$ was added. ${ }^{e} 2,4,6-\mathrm{Mes}_{-} \mathrm{Acr}^{+} \cdot \mathrm{ClO}_{4}{ }^{-} \mathbf{1 1}$ was used as photocatalyst.

Based on this hypothesis, we commenced optimization of the reaction conditions using benzaldehyde (2a) and cyclohexene (1a: 20 equiv) as model substrates, and a combination of $5 \mathrm{~mol} \% \mathrm{CrCl}_{2}$ and $2.5 \mathrm{~mol} \%$ acridinium photoredox catalysts $(2,6-\mathrm{Xyl}-$ $\left.\mathrm{Acr}^{+} \cdot \mathrm{ClO}_{4}^{-} ; \mathbf{1 0}\right),{ }^{16}$ under $430 \mathrm{~nm}$ visible light irradiation at room temperature (Table 1). As expected, the desired reaction did not proceed at all in the absence of chromium complex (entry 1 ). In the presence of $\mathrm{CrCl}_{2}$, however, 8a was obtained in $36 \%$ yield with an excellent diastereomeric ratio (dr) of $>20 / 1$ (entry 2). Encouraged by this finding, we then trialed various chiral ligands for the chromium catalysts, which have previously proven effective for asymmetric NHK reactions (entries 3-6). ${ }^{5}$ However, this resulted in strong retardation of the reaction, with only $\mathbf{L 1}^{17}$ affording $8 \mathbf{a}$ with diminished yield (12\%) and low enantioselectivity (20\% ee). Through extensive screening of other chiral ligands, we identified an Indane-BOX ligand (L5) ${ }^{18}$ which was effective for inducing good enantioselectivity ( $74 \%$ ee), although the yield of $8 \mathbf{a}$ remained unsatisfactory $(8 \%$, entry 7$)$. 
To improve both the reactivity and enantioselectivity, we next investigated the effect of additives. While the addition of $\mathrm{LiCl}^{19}$ or $\mathrm{LiI}^{20}$ was not beneficial (entries 8 and 9), $\mathrm{LiBF}_{4}$ dramatically enhanced the reactivity; 8a was obtained in $40 \%$ yield with $63 \%$ ee (entry 10). Following screening of related cationic lithium salts, we were delighted to discover that addition of $\mathrm{LiClO}_{4}$ increased the enantioselectivity up to $99 \%$ ee (entry 11). Further exploration of alkali and alkali-earth metal perchlorates (entries 12-14) identified as $\mathrm{Mg}\left(\mathrm{ClO}_{4}\right)_{2}$ the optimal additive; $8 \mathbf{a}$ was obtained in $68 \%$ yield with > 20/1 dr and 99\% ee (entry 14). ${ }^{21,22}$ Additionally, use of photocatalyst 11, bearing a mesityl group instead of a xylyl group, did not prove detrimental to these results (entry 15).

With these optimized conditions in hand, our attention turned to the substrate scope. The reaction of cyclohexene (1a) with substituted benzaldehydes afforded products $\mathbf{8 a}-\mathbf{8 g}$ with almost complete diastereo- and enantioselectivity (up to $>20 / 1 \mathrm{dr}$, 99\% ee). The reaction exhibited notable tolerance of aryl halide moieties $(\mathbf{8 b}-\mathbf{8 d})$, and proceeded chemoselectively at the aldehyde functional group in the presence of a ketone (8e) or an ester (8f) functional group. The method was also easily extended to other cyclic alkenes, with both cyclopentene (1b) and cycloheptene (1c) reacting with excellent stereoselectivity $(\mathbf{8 h}-\mathbf{8 k})$.

Furthermore, linear alkenes were also competent substrates. Tetrasubstituted alkene 1d reacted with various aldehydes including ortho-, meta-, and para-substituted benzaldehydes, an electronrich benzaldehyde, and a heteroaromatic aldehyde, affording the corresponding products 81-8q (containing an allylic quaternary carbon) with excellent enantioselectivity. The loading of alkene 1d could be reduced to 2 equiv, likely due to a lowered oxidation potential of $\mathbf{1 d}$ relative to $\mathbf{1 a}-\mathbf{1 c}$. For less reactive aldehydes, such as $o$-tolualdehyde and $p$-methoxy benzaldehyde, the chiral chromium alkoxide complex generated from $\mathrm{CrCl}_{3} \cdot 3 \mathrm{THF}$ and $\mathrm{NaO} t$ - $\mathrm{Bu}^{23}$ exhibited higher catalytic activity than the $\mathrm{CrCl}_{2}$-derived species $(\mathbf{8 m}$ and 8p). We postulate that this is as a result of allychromium species 6 bearing alkoxide ligands $(\mathrm{X}=\mathrm{OR})$ possessing higher nucleophilicity than those bearing electron-withdrawing chloride ligands $(\mathrm{X}=\mathrm{Cl}){ }^{24,25}$ The reaction of aliphatic aldehydes also proceeded with high enantioselectivity $(\mathbf{8 r}-\mathbf{8 u})$ following minor modifications of the reaction conditions (dichloroethane (DCE) as solvent, $20 \mathrm{~mol} \% \mathrm{MgPhPO}_{3}$ additive). In the case of unsymmetric trisubstituted alkene 1e, an inseparable mixture of $\mathbf{8 v}$ and $\mathbf{8 w}$ (itself as a diastereomixture) was produced with moderate regioselectivity (regioisomeric ratio; $r \mathbf{r r}=\mathbf{8 v} / \mathbf{8 w}=1.9 / 1$ ). Nevertheless, both the reactivity and enantioselectivity of $\mathbf{8 v}$ were very high: using $2.5 \mathrm{~mol} \%$ and $0.5 \mathrm{~mol} \%$ loadings of the chromium catalyst and photocatalyst 11 respectively, products were obtained in 97\% combined yield, with $\mathbf{8 v}$ in $95 \%$ ee. Major isomer $\mathbf{8 v}$ presumably derives from prenylchromium species with the chromium atom at the terminal carbon, while minor isomer $\mathbf{8 w}$ originates from 2-methyl but-2enylchromium species with chromium at the terminal carbon. We anticipate that improvement of the regioselectivity for interception of the carbon-centered radical by the metal complex in the case of unsymmetric alkenes will constitute a very important avenue for future research.

Table 2. Substrate Scope of Catalytic Asymmetric Allylation ${ }^{a}$

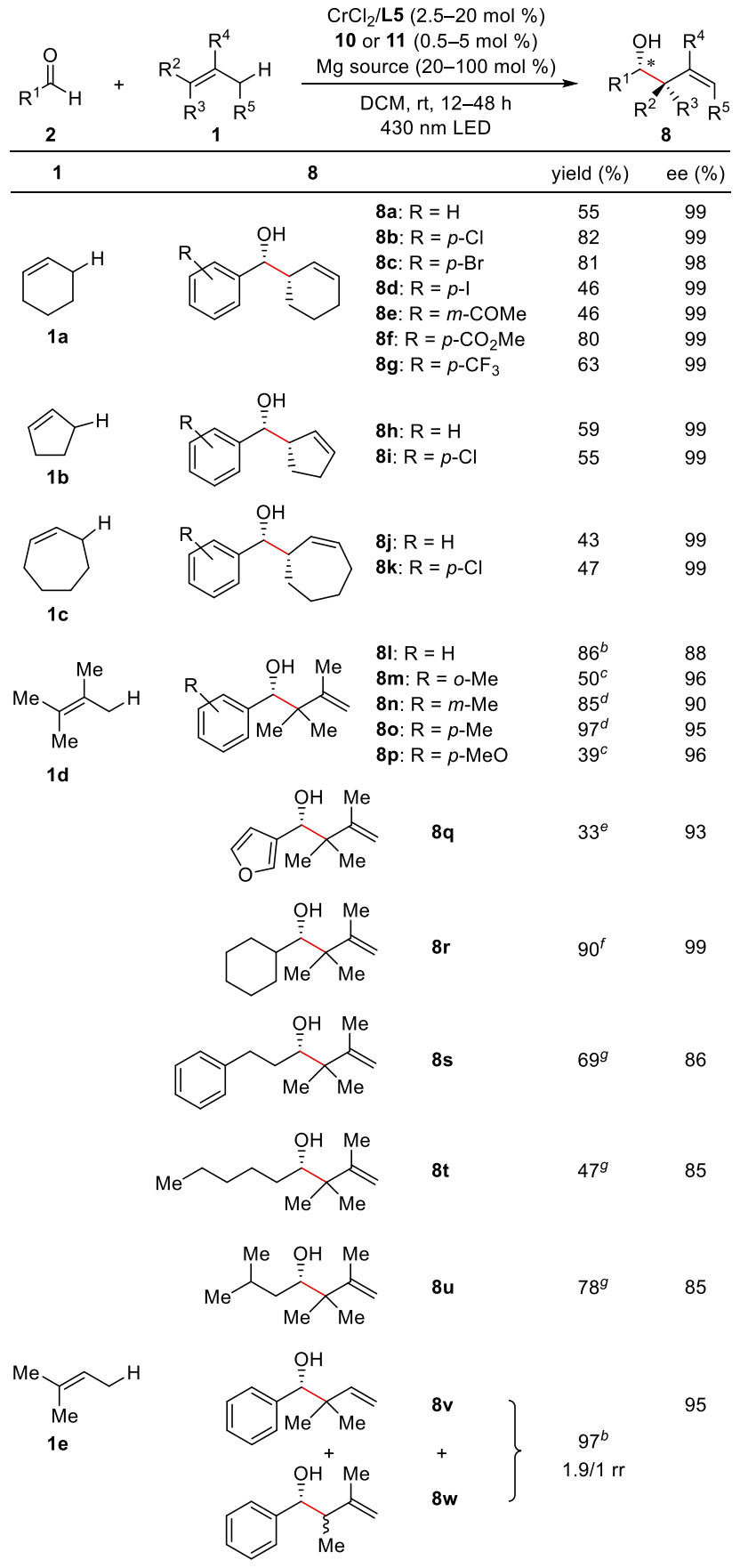

${ }^{a}$ General reaction conditions: aldehyde $2(0.25 \mathrm{mmol})$, alkene $\mathbf{1}$ (5.0 mmol), $\mathrm{CrCl}_{2}(0.0125 \mathrm{mmol}), \mathbf{L 5}(0.0125 \mathrm{mmol}), \mathbf{1 0}$ (0.00625 $\mathrm{mmol})$, and $\mathrm{Mg}\left(\mathrm{ClO}_{4}\right)_{2}(0.25 \mathrm{mmol})$ were reacted in $\mathrm{DCM}(2.5 \mathrm{~mL})$ at room temperature under $430 \mathrm{~nm}$ LED irradiation for $12 \mathrm{~h}$. Yield was isolated yield. The dr was $>20 / 1$ in each case $(\mathbf{8 a}-\mathbf{8 k})$, as determined by ${ }^{1} \mathrm{H}$ NMR analysis of the crude mixture. The ee was determined by chiral stationary HPLC analysis after isolation. ${ }^{b} \mathrm{Al}-$ kene (2 equiv), $\mathrm{CrCl}_{2}(2.5 \mathrm{~mol} \%), \mathbf{L 5}(2.5 \mathrm{~mol} \%), \mathbf{1 1}(0.5 \mathrm{~mol} \%)$, $\mathrm{Mg}\left(\mathrm{ClO}_{4}\right)_{2}$ (1 equiv), and DCM $(0.125 \mathrm{M})$ were used. ${ }^{c}$ Alkene $(20$ equiv), $\mathrm{CrCl}_{3} \cdot 3 \mathrm{THF}$ (10 mol \%), $\mathrm{NaO} t$-Bu (30 mol \%), L5 (10 $\mathrm{mol} \%), 11(1.25 \mathrm{~mol} \%), \mathrm{Mg}\left(\mathrm{ClO}_{4}\right)_{2}$ (1 equiv), and DCM $(0.0625$ M) were used. ${ }^{d}$ Alkene (5 equiv), $\mathrm{CrCl}_{2}(10 \mathrm{~mol} \%), \mathbf{L 5}(10 \mathrm{~mol} \%)$, $11(1.25 \mathrm{~mol} \%), \mathrm{Mg}\left(\mathrm{ClO}_{4}\right)_{2}$ (1 equiv), and $\mathrm{DCM}(0.0625 \mathrm{M})$ were used. ${ }^{e}$ Alkene (20 equiv), $\mathrm{CrCl}_{2}(20 \mathrm{~mol} \%), \mathbf{L 5}$ (20 mol \%), 11 (5 mol \%), $\mathrm{Mg}\left(\mathrm{ClO}_{4}\right)_{2}(1$ equiv), and DCM $(0.0625 \mathrm{M})$ were used. ${ }^{f}$ Alkene (5 equiv), $\mathrm{CrCl}_{2}(10 \mathrm{~mol} \%), \mathbf{L 5}(10 \mathrm{~mol} \%), \mathbf{1 1}(5 \mathrm{~mol} \%)$, $\mathrm{Mg}\left(\mathrm{ClO}_{4}\right)_{2}$ (1 equiv), and DCE $(0.05 \mathrm{M})$ were used. ${ }^{g}$ Alkene $(20$ 
equiv), $\mathrm{CrCl}_{2}$ (20 mol \%), L5 (20 mol \%), 11 (5 mol \%), $\mathrm{MgPhPO}_{3}$ $(20 \mathrm{~mol} \%)$, and DCE $(0.1 \mathrm{M})$ were used. Reaction time was $48 \mathrm{~h}$.

The following experimental results provide key insights regarding the reaction mechanism (see Supporting Information for details). Firstly, the addition of TEMPO (2,2,6,6-tetramethylpiperidinyloxyl) as a radical trapping agent to the reaction between $\mathbf{1 d}$ and 2a under otherwise optimized conditions completely inhibited the desired reaction. A TEMPO adduct of $\mathbf{1 d}$ at the terminal carbon was detected by ${ }^{1} \mathrm{H}$ NMR analysis of the crude mixture after workup. This result supports our hypothesis that the reaction proceeds through carbon-centered radicals derived from alkene $\mathbf{1}$. Secondly, a radical clock experiment using 2-phenylcyclopropylcarbaldehyde and 1d was performed. The reaction proceeded in $77 \%$ yield without any cyclopropane ring-opening. Thus, ketyl radicals derived from aldehydes are not involved in the catalytic cycle. These results, together with the observation that the presence of the chromium complex was essential for the reaction (Table 1, entry 1), are all consistent with our working hypothesis for the reaction mechanism depicted in Figure 2.

In conclusion, we have developed the first catalytic asymmetric allylation of aldehydes using unactivated hydrocarbon alkenes as pronucleophiles. The reaction enabled direct access to enantiomerically and diastereomerically-enriched homoallylic alcohols with high functional group tolerance, starting from readily available and stable substrates. Critical for success was the development of an asymmetric hybrid catalyst system comprising an acridinium photoredox catalyst and a chiral chromium complex catalyst. The hybrid catalysis enabled a key radical-polar crossover process involving catalytic generation of chiral and nucleophilic (i.e., polar) organometallic species from simple alkenes via allylic $\mathrm{C}\left(s p^{3}\right)-\mathrm{H}$ activation. Studies to improve the efficiency of the process further, fully elucidate the reaction mechanism, and expand the substrate scope are currently ongoing.

\section{ASSOCIATED CONTENT}

\section{Supporting Information}

The Supporting Information is available free of charge on the ACS Publications website.

Experimental details and characterization data (PDF)

\section{AUTHOR INFORMATION}

\section{Corresponding Author}

h-mitsunuma@mol.f.u-tokyo.ac.jp

kanai@mol.f.u-tokyo.ac.jp

\section{Notes}

The authors declare no competing financial interests.

\section{ACKNOWLEDGMENT}

This work was supported in part by JSPS KAKENHI Grant Numbers JP17H06442 (M.K.) (Hybrid Catalysis), 17H01522 (M.K.), 17K19479 (M.K.), 18 H05969 (H.M.), and 18H04650 (K.O.) (Hybrid Catalysis).

\section{REFERENCES}

(1) For selected recent reviews on stereoselective allylation of carbonyl compounds, see: (a) Wang, P.-S.; Shen, M.-L.; Gong, L.-Z. TransitionMetal-Catalyzed Asymmetric Allylation of Carbonyl Compounds with Unsaturated Hydrocarbons. Synthesis 2018, 50, 956-967. (b) Sedgwlck, D. M.; Grayson, M. N.; Fustero, S.; Barrlo, P. Recent Developments and Applications of the Chiral Brønsted Acid Catalyzed Allylboration of Carbonyl
Compounds. Synthesis 2018, 50, 1935-1957. (c) Spielmann, K.; Niel, G.; de Figueiredo, R. M.; Campagne, J.- M. Catalytic Nucleophilic 'Umpoled' $\pi$-Allyl Reagents. Chem. Soc. Rev. 2018, 47, 1159-1173. (d) Huo, H.-X.; Duvall, J. R.; Huang, M.-Y.; Hong, R. Catalytic Asymmetric Allylation of Carbonyl Compounds and Imines with Allylic Boronates. Org. Chem. Front. 2014, 1, 303-320. (e) Yus, M.; Gonzalez-Gomez, J. C.; Foubelo, F. Catalytic Enantioselective Allylation of Carbonyl Compounds and Imines. Chem. Rev. 2011, 111, 7774-7854. (f) Yamamoto, H.; Wadamoto, M. Silver-Catalyzed Asymmetric Allylation: Allyltrimethoxysilane as a Remarkable Reagent. Chem. - Asian J. 2007, 2, 692-698. (g) Denmark, S. E.; Fu, J. Catalytic Enantioselective Addition of Allylic Organometallic Reagents to Aldehydes and Ketones. Chem. Rev. 2003, 103, 2763-2794.

(2) (a) Okude, Y.; Hirano, S.; Hiyama, T.; Nozaki, H. Grignard-Type Carbonyl Addition of Allyl Halides by Means of Chromous Salt. A Chemospecific Synthesis of Homoallyl Alcohols. J. Am. Chem. Soc. 1977, 99, 3179-3181. (b) Jin, H.; Uenishi, J.; Christ, W. J.; Kishi, Y. Catalytic Effect of Nickel(II) Chloride and Palladium(II) Acetate on Chromium(II)Mediated Coupling Reaction of Iodo Olefins with Aldehydes. J. Am. Chem. Soc. 1986, 108, 5644-5646. (c) Takai, K.; Tagashira, M.; Kuroda, T.; Oshima, K.; Utimoto, K.; Nozaki, H. Reactions of Alkenylchromium Reagents Prepared from Alkenyl Trifluoromethanesulfonates (Triflates) with Chromium(II) Chloride under Nickel Catalysis. J. Am. Chem. Soc. 1986, 108, 6048-6050.

(3) For selected reviews, see: (a) Gil, A.; Albericio, F.; Á lvarez, M. Role of the Nozaki-Hiyama-Takai-Kishi Reaction in the Synthesis of Natural Products. Chem. Rev. 2017, 117, 8420-8446. (b) Tian, Q.; Zhang, G. Recent Advances in the Asymmetric Nozaki-Hiyama-Kishi Reaction. Synthesis 2016, 48, 4038-4049. (c) Hargaden, G. C.; Guiry, P. J. The Development of the Asymmetric Nozaki-Hiyama-Kishi Reaction. Adv. Synth. Catal. 2007, 349, 2407-2424. (d) Fürstner, A. Carbon-Carbon Bond Formations Involving Organochromium(III) Reagents. Chem. Rev. 1999, 99, 991-1046. (e) Hargaden, G. C.; Guiry, P. J. In Stereoselective Synthesis of Drugs and Natural Products; Andrushko, V.; Andrushko, N., Eds.; John Wiley \& Sons, Inc.: Hoboken, NJ, 2013; pp 347-368.

(4) Fürstner, A.; Shi, N. Nozaki-Hiyama-Kishi Reactions Catalytic in Chromium. J. Am. Chem. Soc. 1996, 118, 12349-12357.

(5) For selected examples of catalytic asymmetric NHK allylation reaction, see: (a) Bandini, M.; Cozzi, P. G.; Melchiorre, P.; Umani-Ronchi, A. The First Catalytic Enantioselective Nozaki-Hiyama Reaction. Angew. Chem., Int. Ed. 1999, 38, 3357-3359. (b) Berkessel, A.; Menche, D.; Sklorz, C. A.; Schröder, M.; Paterson, I. A Highly Enantioselective Catalyst for the Asymmetric Nozaki-Hiyama-Kishi Reaction of Allylic and Vinylic Halides. Angew. Chem., Int. Ed. 2003, 42, 1033-1035. (c) Inoue, M.; Suzuki, T.; Nakada, M. Asymmetric Catalysis of Nozaki-Hiyama Allylation and Methallylation with A New Tridentate Bis(oxazolinyl)carbazole Ligand. $J$. Am. Chem. Soc. 2003, 125, 1140-1141. (d) Kurosu, M.; Lin, M.-H.; Kishi, $\mathrm{Y}$. Fe/Cr- and $\mathrm{Co} / \mathrm{Cr}$-Mediated Catalytic Asymmetric 2-Haloallylations of Aldehydes. J. Am. Chem. Soc. 2004, 126, 12248-12249. (e) Lee, J.-Y.; Miller, J. J.; Hamilton, S. S.; Sigman, M. S. Stereochemical Diversity in Chiral Ligand Design: Discovery and Optimization of Catalysts for the Enantioselective Addition of Allylic Halides to Aldehydes. Org. Lett. 2005, 7, 18371839. (f) Xia, G.; Yamamoto, H. Catalytic Enantioselective Nozaki-Hiyama Allylation Reaction with Tethered Bis(8-quinolinolato) (TBOx) Chromium Complex. J. Am. Chem. Soc. 2006, 128, 2554-2555. (g) Miller, J. J.; Sigman, M. S. Design and Synthesis of Modular Oxazoline Ligands for the Enantioselective Chromium-Catalyzed Addition of Allyl Bromide to Ketones. J. Am. Chem. Soc. 2007, 129, 2752-2753. (h) Zhang, Z.; Huang, J.; Ma, B.; Kishi, Y. Further Improvement on SulfonamideBased Ligand for Catalytic Asymmetric 2-Haloallylation and Allylation. Org. Lett. 2008, 10, 3073-3076. (i) Deng, Q.-H.; Wadepohl, H.; Gade, L. H. The Synthesis of a New Class of Chiral Pincer Ligands and Their Applications in Enantioselective Catalytic Fluorinations and the Nozaki-HiyamaKishi Reaction. Chem. Eur. J. 2011, 17, 14922-14928.

(6) For selected reviews, see: (a) Holmes, M.; Schwartz, L. A.; Krische, M. J. Intermolecular Metal-Catalyzed Reductive Coupling of Dienes, Allenes, and Enynes with Carbonyl Compounds and Imines. Chem. Rev. 2018, 118, 6026-6052. (b) Feng, J.; Holmes, M.; Krische, M. J. Acyclic Quaternary Carbon Stereocenters via Enantioselective Transition Metal Catalysis. Chem. Rev. 2017, 117, 12564-12580. (c) Kim, S. W.; Zhang, W.; Krische, M. J. Catalytic Enantioselective Carbonyl Allylation and Propargylation via Alcohol-Mediated Hydrogen Transfer: Merging the Chemistry of Grignard and Sabatier. Acc. Chem. Res. 2017, 50, 2371-2380.

(7) Schwarz, J. L.; Schäfers, F.; Tlahuext-Aca, A.; Lückemeier, L.; Glorius, F. Diastereoselective Allylation of Aldehydes by Dual Photoredox and Chromium Catalysis. J. Am. Chem. Soc. 2018, 140, 12705-12709. 
(8) The reaction may be classified as a catalytic asymmetric carbonyl ene reaction in a general sense. Substrate scope of the previously-reported carbonyl ene reactions, however, is limited to highly electrophilic aldehydes (e.g. glyoxylic esters) or intramolecular reactions. For reviews of catalytic asymmetric carbonyl ene reactions, see; Clarke, M. L.; France, M. B. The Carbonyl Ene Reaction. Tetrahedron 2008, 64, 9003-9031.

(9) For chiral Bronsted base-catalyzed enantioselective allylation of ketones with special hydrocarbon alkenes (i.e., skipped enynes), see; Wei, X.F.; Xie, X.-W.; Shimizu, Y.; Kanai, M. Copper(I)-Catalyzed Enantioselective Addition of Enynes to Ketones. J. Am. Chem. Soc. 2017, 139, $4647-$ 4650 .

(10) Zhou, R.; Liu, H.; Tao, H.; Yu, X.; Wu, J. Metal-Free Direct Alkylation of Unfunctionalized Allylic/Benzylic $s p^{3} \mathrm{C}-\mathrm{H}$ Bonds via Photoredox Induced Radical Cation Deprotonation. Chem. Sci. 2017, 8, 4654-4659.

(11) For a discussion of the feasibility of the working hypothesis shown in Figure 2 based on the redox potential of each intermediate, see Supporting Information.

(12) For related methods for the generation of organonickel species, see; (a) Joe, C. L.; Doyle, A. G. Direct Acylation of C $\left(s p^{3}\right)-\mathrm{H}$ Bonds Enabled by Nickel and Photoredox Catalysis. Angew. Chem. Int. Ed. 2016, 55, 4040 4043. (b) Ahneman, D. T.; Doyle, A. G. C-H Functionalization of Amines with Aryl Halides by Nickel-Photoredox Catalysis. Chem. Sci. 2016, 7 , 7002-7006. (c) Heitz, D. R.; Tellis, J. C.; Molander, G. A. Photochemica Nickel-Catalyzed C-H Arylation: Synthetic Scope and Mechanistic Investigations. J. Am. Chem. Soc. 2016, 138, 12715-12718. (d) Shields, B. J.; Doyle, A. G. Direct C $\left(s p^{3}\right)-$ H Cross Coupling Enabled by Catalytic Generation of Chlorine Radicals. J. Am. Chem. Soc. 2016, 138, 12719-12722. (e) M. H.; Shurtleff, V. W.; Terrett, J. A.; Cuthbertson, J. D.; MacMillan, D. W. C. Native Functionality in Triple Catalytic Cross-Coupling: $s p^{3} \mathrm{C}-\mathrm{H}$ Bonds as Latent Nucleophiles. Science 2016, 352, 1304-1308. (f) Zhang, X.; MacMillan, D. W. C. Direct Aldehyde C-H Arylation and Alkylation via the Combination of Nickel, Hydrogen Atom Transfer, and Photoredox Catalysis. J. Am. Chem. Soc. 2017, 139, 11353-11356. (g) Gui, Y.-Y.; Liao, L.-L.; Sun, L.; Zhang, Z.; Ye, J.-H.; Shen, G.; Lu, Z.- P.; Zhou, W.-J.; Yu, D.-G. Coupling of $\mathrm{C}\left(s p^{3}\right)-\mathrm{H}$ Bonds with $\mathrm{C}\left(s p^{2}\right)-\mathrm{O}$ Electrophiles: Mild, General and Selective. Chem. Commun. 2017, 53, 1192-1195. (h) Gui, Y.Y.; Chen, X.-W.; Zhou, W.-J.; Yu, D.-G. Arylation of Amide and Urea $\mathrm{C}\left(s p^{3}\right)-\mathrm{H}$ Bonds with Aryl Tosylates Generated In Situ from Phenols. Synlett 2017, 28, 2581-2586. (i) Le, C.; Liang, Y.; Evans, R. W.; Li, X.; MacMillan, D. W. C. Selective $s p^{3}$ C-H Alkylation via Polarity-Match-Based Cross-Coupling. Nature 2017, 547, 79-83. (j) Deng, H.-P.; Fan, X.-Z.; Chen, Z.-H.; Xu, Q.-H.; Wu, J. Photoinduced Nickel-Catalyzed Chemo- and Regioselective Hydroalkylation of Internal Alkynes with Ether and Amide $\alpha$ Hetero C $\left(s p^{3}\right)-$ H Bonds. J. Am. Chem. Soc. 2017, 139, 13579-13584. (k) Gui, Y.-Y.; Wang, Z.-X.; Zhou, W.-J.; Liao, L.-L.; Song, L.; Yin, Z.-B.; Li, J.; Yu, D.-G. Arylation of Aniline C $\left(s p^{3}\right)-\mathrm{H}$ Bonds with Phenols via an In Situ Activation Strategy. Asian J. Org. Chem. 2018, 7, 537-541. (1) Fuse, H.; Kojima, M.; Mitsunuma, H.; Kanai, M. Acceptorless Dehydrogenation of Hydrocarbons by Noble-Metal-Free Hybrid Catalyst System. Org. Lett. 2018, 20, 2042-2045. (m) Go, S. Y.; Lee, G. S.; Hong, S. H. Highly Regioselective and E/Z-Selective Hydroalkylation of Ynone, Ynoate, and Ynamide via Photoredox Mediated Ni/Ir Dual Catalysis. Org. Lett. 2018, 20, 4691-4694. (n) Twilton, J.; Christensen, M.; DiRocco, D. A.; Ruck, R. T.; Davies, I. W.; MacMillan, D. W. C. Selective Hydrogen Atom Abstraction through Induced Bond Polarization: Direct $\alpha$-Arylation of Alcohols through Photoredox, HAT, and Nickel Catalysis. Angew. Chem. Int. Ed. 2018, 57, 5369-5373. (o) Huang, L.; Rueping, M. Direct Cross-Coupling of Allylic $\mathrm{C}\left(s p^{3}\right)-\mathrm{H}$ Bonds with Aryl- and Vinylbromides by Combined Nickel and Visible-Light Catalysis. Angew. Chem. Int. Ed. 2018, 57, 10333-10337. (p) Perry, I. B.; Brewer, T. W.; Sarver, P. J.; Schlutz, D. M.; DiRocco, D. A.; MacMillan, D. W. C. Direct Arylation of Strong Aliphatic C-H Bonds. Nature 2018, 560, 70-75. (q) Shen, Y.; Gu, Y.; Martin, R. $s p^{3} \mathrm{C}-\mathrm{H}$ Arylation and Alkylation Enabled by the Synergy of Triplet Excited Ketones and Nickel Catalysts. J. Am. Chem. Soc. 2018, 140, 12200-12209. (r) Ackerman, L. K. G.; Alvarado, J. I. M.; Doyle, A. G. Direct C-C Bond Formation from Alkanes Using Ni-Photoredox Catalysis. J. Am. Chem. Soc. 2018, 140 , DOI: $10.1021 /$ jacs.8b09191.

(13) For related methods for the generation of organopalladium species, see; (a) Kato, S.; Saga, Y.; Kojima, M.; Fuse, H.; Matsunaga, S.; Fukatsu, A.; Kondo, M.; Masaoka, S.; Kanai, M. Hybrid Catalysis Enabling RoomTemperature Hydrogen Gas Release from N-Heterocycles and
Tetrahydronaphthalenes. J. Am. Chem. Soc. 2017, 139, 2204-2207. (b) Sharma, U. K.; Gemoets, H. P. L.; Schröder, F.; Noël, T.; Van der Eycken, E. V. Merger of Visible-Light Photoredox Catalysis and $\mathrm{C}-\mathrm{H}$ Activation for the Room-Temperature C-2 Acylation of Indoles in Batch and Flow. ACS Catal. 2017, 7, 3818-3823.

(14) For a related method for the generation of organocobalt species, see; Thullen, S. M.; Rovis, T. A Mild Hydroaminoalkylation of Conjugated Dienes Using a Unified Cobalt and Photoredox Catalytic System. J. Am. Chem. Soc. 2017, 139, 15504-15508.

(15) For the generation of chiral organometallic species through homolytic cleavage of a stable $\mathrm{C}\left(s p^{3}\right)-\mathrm{H}$ bond and subsequent oxidative trap by a chiral metal complex, which was applied to a catalytic asymmetric coupling reaction (oxidative benzylic $\mathrm{C}\left(s p^{3}\right)-\mathrm{H}$ cyanation), see; Zhang, W.; Wang, F.; McCann, S. D.; Wang, D.; Chen, P.; Stahl, S. S.; Liu, G. Enantioselective Cyanation of Benzylic C-H Bonds via Copper-Catalyzed Radical Relay. Science 2016, 353, 1014-1018. One preliminary example (54\% ee) with this reaction pattern was also described in ref $12(\mathrm{q})$.

(16) Tsudaka, T.; Kotani, H.; Ohkubo, K.; Nakagawa, T.; Tkachenko, N. V.; Lemmetyinen, H.; Fukuzumi, S. Photoinduced Electron Transfer in 9Substituted 10-Methylacridinium Ions. Chem. Eur. J. 2017, 23, 1306-1317.

(17) Chen, C.; Tagami, K.; Kishi, Y. Ni(II)/Cr(II)-Mediated Coupling Reaction: an Asymmetric Process. J. Org. Chem. 1995, 60, 5386-5387.

(18) Desimoni, G.; Faita, G.; Jørgensen K. A. $C_{2}$-Symmetric Chiral Bis(Oxazoline) Ligands in Asymmetric Catalysis. Chem. Rev. 2006, 106, 3561-3651.

(19) Choi, H.-w.; Wan, Z.-K.; Nakajima, K.; Demeke, D.; Kang, F.-A.; Kishi, Y. Asymmetric Ni(II)/Cr(II)-Mediated Coupling Reaction: Stoichiometric Process. Org. Lett. 2002, 4, 4431-4434.

(20) Wessjohann, L. A.; Gabriel, T. Chromium(II)-Mediated Reformatsky Reactions of Carboxylic Esters with Aldehydes. J. Org. Chem. 1997, 62, 3772-3774.

(21) The role of $\mathrm{Mg}\left(\mathrm{ClO}_{4}\right)_{2}$ is yet to be fully elucidated. We speculate that aldehydes coordinate to $\mathrm{Mg}\left(\mathrm{ClO}_{4}\right)_{2}$ acting as a Lewis acid, resulting in the activation of the electrophile. In addition, $\mathrm{Mg}\left(\mathrm{ClO}_{4}\right)_{2}$ may stabilize ion pair 3, favoring the single-electron photooxidation of $\mathbf{1}$. See; (a) Thompson, P. A.; Simon, J. D. Electrolyte effects on the energetics and dynamics of intermolecular electron transfer reactions. J. Am. Chem. Soc. 1993, 115, 5657-5664. (b) Bockman, T. M.; Hubig, S. M.; Kochi, J. K. Kinetic Isotope Effects for Electron-Transfer Pathways in the Oxidative $\mathrm{C}-\mathrm{H}$ Activation of Hydrocarbons. J. Am. Chem. Soc. 1998, 120, 2826-2830. (c) Yabe, T.; Kochi, J. K. Contact Ion Pairs. Picosecond Dynamics of Solvent Separation, Internal Return, and Special Salt Effect. J. Am. Chem. Soc. 1992, 114, 44914500. (d) Grosso, V. N.; Previtali, C. M.; Chesta, C. A. Salt-induced Charge Separation in Photoinduced Electron Transfer Reactions. The Effect of Ion Size. Photochem. Photobiol. 1998, 68, 481-486. (e) Marcus, R. A. Ion Pairing and Electron Transfer. J. Phys. Chem. B 1998, 102, 10071-10077. (f) Kluge, T.; Knoll, H. Influence of Redoxinert Counterions on Photoinduced Intermolecular Electron Transfer Rates in Dichloromethane. Photochem. Photobiol. A 2000, 130, 95-100. (g) Vakarin, E. V.; Holovko, M. F.; Piotrowiak, P. Ion-Pairing Effects in Intramolecular Electron Transfer. Chem. Phys. Lett. 2002, 363, 7-12. (h) Okamoto, K.; Ohkubo, K.; Kadish, K. M.; Fukuzumi, S. Remarkable Accelerating Effects of Ammonium Cations on Electron-Transfer Reactions of Quinones by Hydrogen Bonding with Semiquinone Radical Anions. J. Phys. Chem. A 2004, 108, 10405-10413.

(22) We assume that chiral ligand $\mathbf{L 5}$ remains coordinated to the chromium atom during the reaction in the presence of stoichiometric $\mathrm{Mg}\left(\mathrm{ClO}_{4}\right)_{2}$; the reaction between $1 \mathbf{a}$ and $\mathbf{2 a}$ did not proceed at all by premixing of $\mathbf{L 5}$ with $\mathrm{Mg}\left(\mathrm{ClO}_{4}\right)_{2}$. See Supporting Information for details. Studies are ongoing to clarify the role of $\mathrm{Mg}\left(\mathrm{ClO}_{4}\right)_{2}$.

(23) Mahendra, K. N.; Mehrotra, R. C. Preparation and Reactions of Chromium(III)alkoxides. Synth. React. Inorg. Met.-Org. Chem. 1990, 20, 963-973.

(24) Sugimoto, K.; Aoyagi, S.; Kibayashi, C. Enantioselective Allylation of Aldehydes with (Dialkoxyallyl)chromium(III) Complexes. J. Org. Chem 1997, 62, 2322-2323.

(25) In the reaction of $p$-methoxy benzaldehyde and 1d, NMR yields of $\mathbf{8 p}$ were $33 \%$ and $62 \%$ by using $\mathrm{CrCl}_{2}$ and $\mathrm{CrCl}_{3} \cdot 3 \mathrm{THF}-\mathrm{NaO} t$ - $\mathrm{Bu}$ catalysts, respectively. 


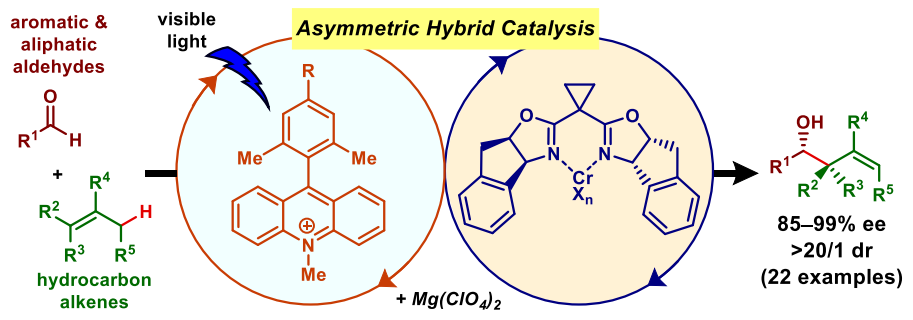

